\title{
Translating research into practice: how are guidelines implemented?
}

\author{
M.R. Partridge
}

Translating research into practice: how are guidelines implemented? M.R. Partridge. (C) ERS Journals Ltd 2003.

ABSTRACT: Numerous guidelines have now been produced both nationally and internationally for the management of respiratory and nonrespiratory disease. They should be regarded as useful tools designed to aid the busy clinician, but their method of production, their value and especially their applicability to primary care and to low income countries need to be assessed critically.

The production of guidelines needs to be carefully incorporated into a planned dissemination and implementation programme. This is likely to be most successful when use is made of interactive educational methods associated with intraconsultation prompting and use of reminders. Updating and life-long learning is necessary and guideline revisions need to be closely incorporated into continuing medical education programmes. National campaigns, the use of media and the "training" of patients to make them more effective partners in healthcare can all enhance a beneficial change in health professional behaviour.

Recent research has enhanced the knowledge of a wide range of respiratory conditions and very effective therapies now exist for many conditions. However, too little attention is often given to the ways in which care is organised and to the important aspects of management that are nonpharmacological. When dealing with long-term conditions, long-term supervision and the teaching of self-management skills are as important as the prescription.

In many parts of the world the ideals, as laid out in guidelines, remain dreams and will continue to be dreams until there is some global redistribution of wealth. Only then will research be translated into practice everywhere.

Eur Respir J 2003; 21: Suppl. 39, 23s-29s.

\author{
Correspondence: M.R. Partridge \\ Imperial College of Science \\ Technology and Medicine \\ Faculty of Medicine - NHLI Division \\ Charing Cross Hospital Campus \\ St Dunstan's Road \\ London \\ W6 8RP \\ UK \\ Fax: 442088467999 \\ E-mail: m.r.partridge@.ic.ac.uk
}

Keywords: Asthma

chronic obstructive pulmonary disease dissemination

guidelines

implementation

Received: June 262002

Accepted after revision: August 52002
Respiratory physicians worldwide deal with diseases that range from tuberculosis to asthma, chronic obstructive pulmonary disease (COPD) to fibrosing alveolitis, pneumonia to cystic fibrosis, and lung cancer to asbestosis. Depending on the country in which they work, they may also have a significant responsibility in the critical care arena. Allergists similarly may care for those with conditions which vary from eczema to anaphylaxis, rhinitis to drug reactions, and asthma to food allergy. The primary care physician cares for everything! To help all of these healthcare professionals, enthusiasts and professional groups have produced an ever-increasing evidence-based plethora of guidelines covering all of the common diseases. Over 2,200 guidelines exist in the USA and the British Thoracic Society (BTS) currently has guidelines available on $>20$ subjects in the field of respiratory medicine (table 1). Internationally the Global Initiative for Asthma (GINA) [2] and Global Obstructive Lung Disease (GOLD) [3] guidelines on asthma and COPD, respectively, have received widespread recognition. Much work has gone into the production of these guidelines and the new BTS/Scottish Intercollegiate Guidelines Network (BTS/ SIGN) Asthma Guidelines, for example, will have cost
$>£ 100,000$ to produce. Therefore, a number of questions arise regarding such guidelines and these include the following. 1) Why are there guidelines? 2) Are the guidelines useful to the nonspecialist and relevant to primary care? 3) Do the guidelines apply equally to low income countries? 4) What are the barriers to the use of guidelines? 5) How can guidelines be disseminated and implemented?

\section{Why are there guidelines?}

The number of research papers published each year is now so large that even in relatively narrow fields it has become impossible for any one individual to peruse all new data and assimilate the conclusions. Even concentrating on reviews rather than on original articles it is perhaps salutary to note that there are 102 reviews in the Cochrane Airways Group alone and most respiratory physicians would also need to read the reviews produced by the Lung Cancer Group, Acute Respiratory Infections Group, the Tobacco Addiction Group, the Cystic Fibrosis Group and the Infectious Diseases Group. Therefore, guidelines act first as a summary of research. Most new guidelines 
Table 1. - Guidelines on the following respiratory subjects have been produced by the British Thoracic Society (BTS)

The management of pneumonia in adults

The management of pneumonia in children

The management of asthma

The management of COPD

Managing passengers with respiratory disease planning air travel

Noninvasive ventilation in acute respiratory failure

BTS statement on malignant mesothelioma

BTS statement on pulmonary rehabilitation

Diagnostic flexible bronchoscopy

The selection of patients with lung cancer for surgery

Control and prevention of tuberculosis

Management of opportunist and mycobacterial infections

The diagnosis, assessment and treatment of diffuse

parenchymal lung disease in adults

Chemotherapy and management of tuberculosis in the UK

BTS recommendations to respiratory physicians for organising the care of patients with lung cancer

Suspected acute pulmonary embolism: a practical approach Guidelines on the management of COPD

Current best practice for nebuliser treatment

Guidelines for the management of spontaneous pneumothorax

COPD: chronic obstructive pulmonary disease. Information taken from [1].

are evidence based and result from systematic reviews where each recommendation can be traced back to the supporting studies. Guidelines also potentially enable the delivery of more uniform care, as nothing confuses a patient more than to receive differing advice from different healthcare professionals. Having a standard set of guidelines available also facilitates audit and the overall aim is to improve standards of healthcare.

\section{Are the guidelines useful to the nonspecialist and relevant to primary care?}

Whether a patient is cared for by a specialist or a generalist they deserve to be managed in the best possible way, and this way is usually as outlined in management guidelines. However, the problem is that most guidelines are lengthy. The GINA Workshop Report [2], for example, is 176 pages long and even the pocket guide consists of 28 pages. Whilst a specialist in the field may be expected to read a document of such length, the generalist caring for people with multiple diseases of many systems will not have the time to do so. This issue needs to be addressed in the dissemination and implementation process, where key messages need to be elicited and succinctly presented. It is also important to ensure that any recommendations are practical and feasible in primary care, and this applies not only to investigations such as spirometry, which is not always available, but also to recommendations regarding management. For example, many guidelines include advice regarding the assessment of variability in the diagnosis of asthma. Some do not stipulate the method by which such variability should be calculated (e.g. amplitude percentage best $=($ highest-lowest/highest $\times 100))$, but even if the method is stated it is realistic to realise that such calculations will not be made in a busy general practice. A problem of greater magnitude for guideline use in primary care is that the patients rarely approach the primary care physician with a clear diagnostic label attached to them. A symptom- as opposed to a disease-based approach to management is therefore preferable in primary care and this also needs to address the fact that symptoms of respiratory disease such as breathlessness are shared with diseases of many other body systems.

\section{Do guidelines apply equally to low income countries?}

Most of the studies upon which guideline recommendations are based would have been carried out in countries with well developed healthcare resources and good facilities. This may mean that recommendations are made that cannot be justified in different ethnic groups, and different races may metabolise drugs differently. Guidelines also need to acknowledge that there may be differing cultural misconceptions and behavioural issues in differing populations. Studies in India, for example, have shown that mothers express concern and very high levels of denial when confronted with a diagnosis of asthma in their children [4]. It is possible that risk versus benefit arguments regarding therapeutic decisions also vary between nations. A risk of steroid therapy may possibly be greater if the patient is malnourished or paradoxically less relevant if life expectancy is anyway low. Guideline recommendations may also be inappropriate if, for example, they recommend referral to a specialist respiratory paediatrician if one does not exist in that healthcare system or if the nearest is 250 miles away.

The availability of therapies recommended in guidelines may be limited because of cost or supply problems. In one study, inhaled steroids were found to be available in only 15 of 24 countries surveyed in Africa and Asia and, where they were available, the medium cost of a beclomethasone $50 \mu \mathrm{g}$ inhaler was $20 \%$ (range $6.8-100$ ) of the average local monthly income [5]. In such countries substitute therapies may have to be used, but these have often not been subjected to trials to determine their relative efficacy in that healthcare system. Perhaps this can only truly be addressed when global inequalities in healthcare expenditure have been dealt with.

\section{What are the barriers to use of guidelines?}

If health professional behaviour is to be influenced and research findings are to be implemented in clinical practice, the barriers which may exist to such implementation must first be identified. Some have already been addressed but others exist and may lie within the health professional, within the system or within the culture. In some circumstances the barrier may reflect an issue or disease not being on a Government or Health Department agenda and this may reflect either competing demands or sometimes a lack of data to demonstrate the size of a problem. It is important within each country to identify the size of 
each of these barriers and each may need different approaches if they are to be overcome.

CABANA et al. [6] have identified a number of barriers to physician adherence with guidelines and these are listed in table 2. Similar results have been suggested from recent primary care studies in the UK [7]. From a global view point, an additional set of barriers may arise. In many countries of the world the health picture is dominated by communicable diseases. Asthma and COPD, for example, may not yet appear on politicians' and health officials' agendas. This is despite high published prevalence rates of exerciseinduced asthma in many countries, including 5.8\% in Zimbabwe [8] and 4.7\% in Ghana [9], and data from the International Study of Asthma and Allergies in Children (ISAAC) showing a $\% \%$ prevalence of asthma amongst Pakistani school children [10].

Just because a country has a major problem with communicable diseases does not justify a lack of care for those with "newer" noncommunicable diseases and forward planning is required to adjust resources for a changing pattern of disease. COPD, for example, is acknowledged by the World Health Organization (WHO) as an increasing problem and it is estimated that it will move from being the 12th cause of disabilityadjusted life years lost worldwide in 1990, to being the 5 th biggest cause of such loss in 2020.

The trend in many countries is a move from a burden of communicable to noncommunicable diseases, with the trend being slower in sub-Saharan Africa. The shift from communicable to noncommunicable diseases needs to be accompanied by a change in the pattern and type of healthcare on offer. This involves a move from care being provided for a series of acute illnesses to long-term care being provided for those with long-term disorders. This necessitates more emphasis being placed upon enhancing compliance, giving control to the person with the condition (self-management), group support and alternative methods of follow-up.
However, the major economic barrier that exists for many countries needs to be recognised. Many countries of the world have too little wealth to cater for simple infectious diseases, let alone sufficient wealth to face the challenge of healthcare for those with long-term conditions. Expenditure on health per capita per year (expressed in US dollars) ranges from $<15$ per year in many of the poorest countries of the world to $>4,000$ per year in the USA. As the WHO's Commission on Macro Economics and Health made clear, a reduction in this gap would benefit not only the health but the economy of the poorer countries, and rich countries in turn would benefit from this economic growth [11].

\section{How can guidelines be disseminated and implemented?}

Dissemination and implementation have been defined by others [12-14] as follows: dissemination is an "educational intervention that aims at influencing targeted clinicians attitudes to, and awareness, knowledge and understanding of, a set of guidelines"; implementation is "turning changes in attitude and knowledge into changes in medical practice".

Dissemination may involve the following: 1) publication in professional journals; 2) postal distribution to relevant groups; 3) incorporation within continuing medical education/continuing professional development programmes; 4) educational initiatives focussing specifically on guidelines (e.g. symposia); and 5) the use of lay and medical media.

Grimshaw and Russell [14] have suggested that specific educational interventions have the greatest probability of being effective, followed by continuing medical education. Publication alone is unlikely to be effective. One review of nineteen studies of dissemination of guidelines concludes that this act alone failed to invoke any significant behaviour change [15]. Nevertheless, as CABANA et al. [6] pointed out, a significant barrier to use of guidelines is lack of awareness or

Table 2. - Barriers to physician adherence to guidelines

\begin{tabular}{|c|c|}
\hline Barrier & Comments \\
\hline Lack of awareness & Guidelines have little impact if physicians are not aware of them \\
\hline Lack of familiarity & $\begin{array}{l}\text { Physicians must have copies of guidelines and be familiar enough with their details to } \\
\text { use them correctly }\end{array}$ \\
\hline Lack of agreement & $\begin{array}{l}\text { Physicians may disagree with the concept of guidelines in general, or with a guideline's } \\
\text { recommendations because of interpretation of the evidence, the guideline's applicability to } \\
\text { their patients or lack of confidence in the guideline's author(s) }\end{array}$ \\
\hline Lack of self-efficacy & $\begin{array}{l}\text { Physicians may believe that they cannot perform the recommendations of a guideline } \\
\text { because they lack appropriate training or experience and this is often associated with } \\
\text { preventative health guidelines that recommend physicians counsel or educate patients }\end{array}$ \\
\hline $\begin{array}{l}\text { Lack of outcome } \\
\text { expectancy }\end{array}$ & $\begin{array}{l}\text { Even if physicians believe that they can perform a guideline recommendation, they may not } \\
\text { believe that it will affect patient outcomes. This may result from previous underwhelming } \\
\text { outcomes following performance of guideline recommendations and this is also associated } \\
\text { with preventive health guidelines that recommend that physicians counsel or educate patients }\end{array}$ \\
\hline $\begin{array}{l}\text { The inertia of } \\
\text { previous practice }\end{array}$ & $\begin{array}{l}\text { Physicians may not follow guidelines that recommend changes in practice, despite proper } \\
\text { knowledge of and attitudes about a guideline }\end{array}$ \\
\hline $\begin{array}{l}\text { External- or } \\
\text { practice-related } \\
\text { barriers }\end{array}$ & $\begin{array}{l}\text { Physicians may be unable to overcome barriers in their practice environment, such as lack } \\
\text { of time, lack of reimbursement for following guidelines or limited staff. Physicians may be } \\
\text { unable to reconcile patient preferences with guideline recommendations and guidelines } \\
\text { themselves may be confusing or unclear }\end{array}$ \\
\hline
\end{tabular}

Modified from [6]. 
familiarity with their existence and content. Dissemination is therefore necessary but will only achieve change if combined with implementation.

Dissemination can be a costly process. The example of the 1997 dissemination of the BTS guidelines is important [16]. A very high level of professional awareness was achieved by targeting specific groups of healthcare professionals in different ways. These were offered full sets of guidelines, summary charts, teaching materials or wall charts, as appropriate, and invited to interactive regional meetings. A total of 61,000 healthcare professionals were mailed the guidelines with $9.3 \%$ requesting more material. A further 45,500 general practitioners and practice nurses were sent a follow-up mailing and $7.3 \%$ requested further material. Some 14,000 primary care physicians were invited to 19 regional meetings and $12.5 \%$ responded. A parallel media exercise was designed to place the subject on health professionals' agendas and raise public awareness of the new guidelines. In determining what to disseminate, five key points contained within the new guidelines were equally promoted in the slide set sent to the specialists, in the summary charts for primary care and in media stories placed in both the lay and medical press. Pre- and postlaunch surveys of doctors and nurses in primary care showed that there was very widespread knowledge of the launch of the new guidelines, but when they were asked to spontaneously mention some of the key changes in the guidelines the recommendation regarding the introduction of long acting inhaled $\beta$-agonists was better known than the fact that the guidelines also promoted self-management plans and placed an emphasis on accurate diagnosis.

In retrospect, lessons can probably be learnt from the experience of this dissemination process. Disseminating full copies of the guidelines was probably appropriate to the specialist but it was extremely costly and it would have been cheaper and more appropriate to distribute brief summaries, with background documents being available on request or on websites. The series of regional meetings were also costly and difficult to arrange and the percentage of primary care health professionals attending was limited. Whilst an attempt was made to construct these meetings such that a paediatrician and respiratory physician gave only a short overview of their sections of the guidelines and to follow this with a widespread discussion led by a local opinion leader, the importance of local opinion leaders is unclear and one review of eight studies suggested equivocal benefit [17]. The meetings cannot be said to have been truly (educationally) interactive and as a Cochrane Review has pointed out [18], whilst educational meetings and printed educational materials are the two most common types of continuing education for health professional, studies that have been done to assess the effect of these meetings on health professional behaviour and healthcare outcomes are inevitably diverse in type and often not fully reported. When ten studies of interactive workshops were analysed, there were moderate or moderately large effects in six (all of which were statistically significant) and small effects in four. For interventions that combined workshops and didactic presentations there were moderate or moderately large effects in twelve comparisons (eleven of which were statistically significant) and smaller effects in seven. In seven comparisons of didactic presentations there were no statistically significant effects, with the exception of one out of four outcome measures in one study. As the reviewers conclude "interactive workshops can result in moderately large changes in professional practice. Didactic sessions alone are unlikely to change professional practice".

The dissemination and implementation process could therefore be better arranged to take the intervention nearer to the doctor/patient interaction and to make it interactive. Academic detailing has also been suggested as a beneficial intervention and this is synonymously referred to by others as outreach visits or face-to-face teaching, but essentially involves a personal visit by a trained person to a healthcare provider in his or her own setting. A Cochrane Review identified eighteen studies involving $>1,896$ physicians and all of the outreach visit interventions consisted of several components including written material and conferences. Reminders or audit and feedback complemented some visits. Process change was observed in all studies but only one measured a patient outcome and there were few studies looking at the cost effectiveness of such academic detailing. However, such place of work (outreach) teaching appears to be a promising way of altering health professional behaviour, perhaps especially concerned with prescribing [19]. Following this with the use of some form of intraconsultation prompting of the doctors' behaviour is also likely to be beneficial. The use of a prompt stamp within consultations (designed to elicit symptoms and make objective measurements and check patient skills) has been shown to influence process and prescribing habits [20], as has the use of algorithms in emergency departments [21].

The more that recommendations are related to the individual patient, the greater the effectiveness. The potential for computerised decision support systems in this area would appear to be great. HunT et al. [22] looked at 68 studies and showed that whilst computerised decision support systems had limited usefulness in diagnosis, their use did lead to improvements in decisions on medication dosages, the giving of preventative advice and general clinical management.

If the evidence suggests that guidelines can change clinical practice, and are most likely to be successful when local circumstances are taken into account and are accompanied by active educational interventions [23], what do we teach in primary care and are there other problems? Implementation programmes need to recognise that guidelines are usually specific to the management of one disease and yet there may be 30-40 respiratory diseases, and the symptoms of many respiratory diseases such as breathlessness are shared with disorders of other systems. With regards to breathlessness, it needs to be emphasised that a patient complaining of breathlessness may have symptoms due to any of the following: 1) lung disease, 2) heart disease, 3) pulmonary vascular disease, 4) neuromuscular disease (diaphragm failure), 5) systemic disorders (anaemia, obesity, hyperthyroidism) or 6) psychogenic factors. It then needs to be emphasised that if the cause of those symptoms is thought to be due to a 
respiratory disorder, it has to be determined whether that disorder is due to an infection or to pulmonary vascular disease, and then make a decision as to whether the patient is likely to have an airway disorder or a small lung disorder. The importance of spirometry in aiding this differentiation, wherever possible, cannot be over emphasised. However, it also needs to be understood that if a patient has, for example, a cough, wheeze, breathlessness and obstructive spirometry, this could reflect either generalised narrowing of the medium or smaller airways (as is found in asthma or COPD) or a localised narrowing of a larger, more central airway, and the differential diagnosis would then include a bronchial carcinoma, inhaled foreign body, post-tracheostemy stenosis etc.

Compliance with guideline recommendations is low when recommendations are complex [24] and it is sometimes helpful, especially when trying to teach enhanced diagnostic skills, to use simple algorithms or flow diagrams or to teach how to differentiate the cause of symptoms by looking, for example, at the rate of onset of the symptom. Table 3 shows an example of how this may be done for the symptom of breathlessness. It is important to stress that such educational activities are not always as complicated as they sound and can have surprisingly long-lasting beneficial effects. CLARK et al. [25], for example, have reported on the long-term effects of asthma education for physicians on patient satisfaction and use of health service resources. In a randomised controlled trial they showed how two faceto-face, interactive group meetings lasting $2.5 \mathrm{~h}$ over a 2-3 week period enabled physicians to be taught the contents of guidelines, how to give self-management advice, personal asthma action plans and how to communicate better. Two years after the intervention the trained physicians were more likely than control physicians to practice according to guidelines and to give asthma action plans. Furthermore, the parents of the children seen by the intervention physicians scored them more highly and the children had less hospitalisations or emergency room attendances. In addition, their consultations took no longer.

Further reinforcement of guideline messages may be obtained by audit. Audit packages that use patientspecific feedback in relation to guidelines have been shown by NeviLle and co-workers $[26,27]$ to improve asthma outcomes both for acute attacks and routine review. Others have also demonstrated improvement following audit but this may preferentially affect different aspects of management, for example prescribing. In no study were the effects more than minor to moderate [28, 29].
A further form of reinforcement may be the patients. Patients can be taught how to become more effective partners within consultations. Teaching patients how to present their symptoms and history more clearly, and teaching them how to question the doctor and verify information received may dramatically improve satisfaction and compliance and thus health outcomes. One study in an American family practice showed that this was best done by sending patients a 14-page booklet prior to the appointment, with the booklet being designed to encourage logical information giving and describing of symptoms, sample questions regarding the seeking of information and advice as to how to check understanding and clarify the information received $[30,31]$.

Compliance may also be enhanced by giving control of their condition to the patients themselves. GIBSON et al. [32], reviewing all published studies of selfmanagement education in asthma compared to usual care, showed how self-management reduced hospitalisations, emergency room visits, unscheduled visits to the doctor and days off work or school. The results were best where self-management included the giving of a written asthma action plan. In a study of 39 people with asthma who were educated by means of a brochure, followed by two 2-h educational sessions and receipt of a written action plan, GALLEFoss and BAKKE [33] were able to show how 1 yr later the patients given control of their own condition were more likely than the uneducated patients to collect prescribed medication from the pharmacy. The strength of evidence in favour of self-management education in asthma (but not in COPD) is why the subject is emphasised so strongly in current guidelines.

Attention to the way in which care is organised for those with respiratory disease may also be an essential part of the effective transfer of research knowledge into practice. Patients' preferences for asthma care have been shown to include factors such as the following [34]: 1) the extent to which the doctor gives sufficient time to listen to what a patient has to say, 2) seeing the same doctor on each occasion, 3) the extent to which treatment seems to relieve the patient's symptoms, and 4) low travel costs of attending for an asthma consultation.

Organising services to address these issues may be helpful and a common understanding should be elicited by asking patients questions such as the following. 1) What is it you want of me/what can I do for you? 2) How do you see your condition going in the future? 3) Some people have concerns about steroids, how do you feel? 4) How does your condition effect you

Table 3.-One method of teaching how to assess the cause of breathlessness by reference to its onset

\begin{tabular}{|c|c|}
\hline Sudden & $\begin{array}{l}\text { Consider: pulmonary embolus, pneumothorax, cardiac rhythm disturbance (possibly post-MI), } \\
\text { dissecting aneurysm or foreign body inhalation }\end{array}$ \\
\hline Over hours/days & $\begin{array}{l}\text { Consider: pneumonia (+/- background COPD), left ventricular failure (maybe valvular, septal } \\
\text { or a complication of } \mathrm{MI}) \text {, pleural effusion, blood loss, lobar collapse, respiratory muscle weakness } \\
\text { (e.g. Guillain Barre) }\end{array}$ \\
\hline Over weeks & $\begin{array}{l}\text { Consider: malignancy, sarcoidosis, fibrosing alveolitis, anaemia, respiratory muscle weakness (e.g. } \\
\text { motor neurone disease) }\end{array}$ \\
\hline Over years & Consider: obesity, COPD, chest wall deformities \\
\hline
\end{tabular}

MI: myocardial infarction; COPD: chronic obstructive pulmonary disease. 
most? 5) How do you feel about your treatment/this prescription?

This should also always be followed up by giving patients written information about their personal treatment. This may need to be quite specific, for in one study, for example, it was shown that in the absence of advice, a third of patients given steroid tablets did what might seem logical and spread the tablet taking throughout the day or took them specifically at a time other than in the morning, which is endocrinologically preferable [35]. Efforts should also be directed at making it easy for patients to attend clinics. Prospective studies have shown that $30 \%$ of patients who failed to attend out-patient appointments did so because they forgot [36]. Sending new patients an information pack telling them when and where to attend, where to park, what to bring, who they will see and what to expect, followed by a supplementary phone call a week before the appointment can reduce nonattendance rates to $\sim 1 \%$ [37].

These patient and organisational aspects of services may also be augmented by mass media interventions. This has been successfully used to enhance the diagnosis of asthma in Australia [38] and has been shown to encourage effective use of services and discourage those of unproven effectiveness across several fields [39].

Would guideline implementation save money? Undertreatment of asthma, for example, has clearly been shown to be associated with morbidity and mortality but better care may enable there to be savings in use of health service resources. A crude analysis by BLAINEY et al. [40] looked at the cost of in-patient treatment if optimal prior management of patients is not achieved. In this analysis patients were reviewed to assess whether the admission could have been prevented. A total of 55 out of 75 hospital admissions for severe asthma were so classified and using 1990/1991 prices this level of "mismanagement" equated to an annual cost of preventable asthma admissions of $£ 44,860$ per 100,000 population.

Self-management programmes in asthma are also cost-effective interventions. The cost:benefit ratio in published studies ranges from $1: 2.5$ to $1: 11.22$; that is the most cost-effective programmes brought a saving of US\$ 11.22 for every dollar spent [41]. In the case of obstructive sleep apnoea syndrome it has been suggested that the correct diagnosis of the condition and implementation of treatment saves $£ 12.30$ for every $£ 1.00$ spent by savings on reduction in road traffic crashes alone [42]. Better care very often equals lower costs.

\section{Conclusions}

The conclusions of this review are as follows. 1) Clinical guidelines need to be evidence based and seen to be scientifically valid. 2) The production of guidelines needs to be part of a continual process that merges with dissemination and implementation activities and audit. 3) The main recommendations contained within guidelines need to be used in everyday clinical consultations and this may involve intraconsultation prompting by means of algorithms, stamps, checklists and patient prompts, or by computerised decision support software. 4) Healthcare professionals have to become lifelong learners if they are to utilise new knowledge and the role of interactive continuing medical education in the implementation of guidelines is of paramount importance. Didactic lectures should be abolished! 5) Patients can be trained to be more effective partners in healthcare and may act as a stimulus to health professional change. 6) Practising according to guidelines usually saves health service resources. 7) For many countries of the world none of this will be achievable until there is some global redistribution of wealth.

\section{References}

1. British Thoracic Society. www.brit-thoracic.org.uk. Last updated: continuous.

2. Global Initiative for Asthma. Global Strategy for Asthma Management and Prevention NHLBI/WHO Workshop Report. National Institute of Health, Publication number 95-3659. Bethesda, Maryland, 1995.

3. Global Initiative for Chronic Obstructive Lung Disease. Global Strategy for the Diagnosis, Management and Prevention of Chronic Obstructive Pulmonary Disease, NHLBI/WHO Workshop Report. National Institute of Health, Publication number 270. Bethesda, Maryland, 2001.

4. Lal A, Kumar L, Malhotra S. Knowledge of asthma among parents of asthmatic children. Indian Pediatr 1995; 32: 649-655.

5. Watson JP, Lewis RA. Are recommended treatments affordable. Thorax 1997; 52: 605-607.

6. Cabana MD, Rand CS, Powe NR, et al. Why don't physicians follow clinical practice guidelines? A framework for improvement. JAMA 1999; 282: 1458-1465.

7. Freeman AC, Sweeney K. Why general practitioners do not implement evidence: a qualitative study. $B M J$ 2001; 323: 1100-1102.

8. Keeley DJ, Neill P, Gallivan S. Comparison of the prevalence of reversible airways obstruction in rural and urban Zimbabwean children. Thorax 1991; 46: 549-553.

9. Addo Yobo EO, Custovic A, Taggart SC, AsafoAgyei AP, Woodcock A. Exercise induced bronchospasm in Ghana: differences in prevalence between urban and rural school children. Thorax 1997; 52: 161-165.

10. The International Study of Asthma and Allergies in Childhood (ISAAC) Steering Committee. Worldwide variation in prevalence of symptoms of asthma, allergic rhinoconjunctivitis, and atopic eczema: ISAAC. Lancet 1998; 351: 1225-1232.

11. World Health Organisation. Macro-economics and health; investing in health for economic development. Report of the commission on macro-economics and health. Geneva, WHO, 2001.

12. Grimshaw JM, Russell IT. Effect of clinical guidelines on medical practice. A systematic review of rigorous evaluations. Lancet 1993; 342: 1317-1322.

13. Grimshaw JM, Russell IT. Achieving health gain through clinical guidelines: Developing scientifically valid guidelines. Qual Health Care 1993; 3: 243-248.

14. Grimshaw JM, Russell IT. Achieving health gain 
through clinical guidelines: Ensuring guidelines change medical practice. Qual Health Care 1994; 3: 345-352.

15. Lomas J. Words without action? The production, dissemination and impact of consensus recommendations. Annu Rev Public Health 1991; 12: 41-65.

16. Partridge MR, Harrison BDW, Rudolph M, Bellamy D, Silverman M. The British Asthma Guidelines their production, dissemination, and implementation. Resp Med 1998; 92: 1046-1052.

17. Thomson MA, Oxman AD, Davis DA, Haynes RB, Freemantle N, Harvey EL. Local opinion leaders to improve health professional practice and healthcare outcomes (Cochrane Review). In: The Conchrane Library, Issue 1. Oxford, Update Software, 1999.

18. Thomson $\mathrm{O}^{\prime}$ Brien MA, Freemantle N, Oxman AD, Wolf F, Davis DA, Herrin J. Continuing education meetings and workshops: effects on professional practice and healthcare outcomes (Cochrane Review). In: The Cochrane Library, Issue 2. Oxford, Update Software, 2002.

19. Thomson $\mathrm{O}^{\prime}$ Brien MA, Oxman AD, Davis DA, Haynes RB, Freemantle N, Harvey EL. Educational outreach visits: effects on professional practice and healthcare outcomes (Cochrane Review). In: The Cochrane Library, Issue 2. Oxford, Update Software, 2002.

20. Feder G, Griffiths C, Highton C, Eldridge S, Spence M, Southgate L. Do clinical guidelines introduced with practice based education improve care of asthmatic and diabetic patients? A randomised control trial in general practice in East London. BMJ 1995; 311: 1473-1478.

21. Town L, Kwong T, Holst P, Beesley R. Use of a management plan for treating asthma in an emergency department. Thorax 1990; 45: 702-706.

22. Hunt DL, Haynes RB, Hanna SE. Affects of computer based clinical decision support system on physician performance and patient outcomes. A systematic review. JAMA 1998; 280: 1339-1346.

23. Getting evidence into practice. NHS centre reviews and dissemination. The University of York. Implementing clinical guidelines: can guidelines be used to improve clinical practice?. Eff Health Care 1994; 5: 115.

24. Grilli R, Lomas J. Evaluating the message: the relationship between compliance rate and the subject of practice guidelines. Med Care 1994; 32: 202-213.

25. Clark NM, Gong M, Shork MA, et al. Long term effects of asthma education for physicians on patient satisfaction and use of health services. Eur Respir $J$ 2000; 16: 15-21.

26. Neville RG, Hoskins G, Smith B, Clark RA. Observations on the structure, process and outcome of asthma care in general practice. Br J Gen Pract 1996; 46: 583-587.

27. Neville RG, Hoskins G, Smith B, Clark RA. How general practitioners manage acute asthma attacks. Thorax 1997; 52: 153-156.
28. Balas EA, Boren SA, Brown GD. Effect of physician profiling on utilisation. J Gen Intern Med 1996; 11: $584-490$.

29. Thomson MA, Oxman AD, Davis DA, Haymen RB, Freemantle N, Harvey EL. Audit and feedback to improve health professional practice and health care outcomes (Parts I \& II) (Cochrane Review). In: The Cochrane Library, Issue 2. Oxford, Update Software, 2002.

30. Cegala DJ, Marinelli T, Post DM. Effects of patient communication skills training on compliance. Arch Pham Med 2000; 9: 57-64.

31. Cegala DJ, McClure L, Marinelli T, Post DM. Effects of patient communication skills training on participation during interviews. Patient Educ Couns 2000; 41: 209-222.

32. Gibson PG, Wilson AJ, Hensley M, Abramson M, Baumen A. The effects of self-management asthma education and regular practitioner review in adults with asthma (Cochrane Review). In: The Cochrane Library, Issue 2. Oxford, Update Software, 2002.

33. Gallefoss F, Bakke PS. The effect of patients education in self-management on compliance in asthma and COPD. Am J Respir Crit Care Med 1999; 160: 2000 2005.

34. Ratcliffe J, Van Haselen R, Buxton M, Hardy K, Colehan J, Partridge M. Assessing patients' preferences for characteristics associated with homeopathic and conventional treatment of asthma: a conjoint analysis study. Thorax 2002; 57: 503-508.

35. Partridge MR, Partridge JSL, Rooney M, Kava T. What time of day do patients take steroid tablets? Resp Med 2001; 95: 90-99.

36. Murdoch A, Rodgers C, Lindsay H, Thant TCK. Why do patients not keep their appointments? J R Soc Med 2002; 95: 284-286.

37. Hardy KJ, O'Brien SV, Furlong NJ. Information given to patients before appointments and it's effect on non-attendance rates. BMJ 2001; 323: 12981300.

38. Bauman A, Antic R, Rubinfeld A. Could it be asthma? The impact of a mass media campaign aimed at raising awareness about asthma in australia. Health Educ Res 1993; 4: 581-587.

39. Grilli R, Ramsay C, Minozzi S. Mass media interventions: effects on health services utilisation (Cochrane Review). In: The Cochrane Library, Issue 2. Oxford, Update Software, 2002.

40. Blainey AB, Beale A, Lomas D, Partridge MR. The cost of acute asthma. How much is preventable? Health Trends 1994; 22: 151-153.

41. Bolton MB, Tilley BC, Kuder J, Reeves T, Schultz LR. The cost and effectiveness of an education programme for adults who have asthma. J Gen Intern Med 1991; 6: 401-407.

42. Douglas NJ, George CFP. Treating sleep apnoea is cost effective. Thorax 2002; 57: 93-94. 